\title{
El presente y sus restos. Arte, literatura e imagen en la estética contemporánea*
}

Fecha de recepción: 8 de febrero de 2019

Fecha de aprobación: 31 de julio de 2019

\section{Resumen}

En las últimas décadas, el campo de la estética y de los estudios sobre el arte participaron de una serie de transformaciones y movimientos que hicieron converger dos problemáticas: los anuncios sobre el fin del arte (y de modo aún más amplio, el fin de sentido, de la historia, de la literatura) y los debates sobre la postautonomía del arte. A partir de los aportes críticos y teóricos de Nelly Richard, Jacques Rancière, Giorgio Agamben, entre otros, este artículo explora la emergencia de la noción de imagen en el escenario contemporáneo para despuntar los sentidos que abogan por la caducidad del arte o, su contracara, por un impulso de innovación de las formas. Ante la apertura de la relación entre arte y literatura, tiene lugar un desplazamiento que es posible leer en el modo en que la crítica argentina contemporánea compone una constelación de sentidos entre imagen, escritura y presente.

Palabras claves: crítica literaria; estética contemporánea; imagen; Jacques Rancière, postautonomía.

Citar: Neuburger, A. (abril-junio de 2020). El presente y sus restos. Arte, literatura e imagen en la estética contemporánea. La Palabra, (37), 41-56. https://doi.org/ 10.19053/01218530.n37.2020.8950

\section{Ana Neuburger}

Universidad Nacional de Córdoba / CONICET

Licenciada en Letras Modernas por la Universidad Nacional de Córdoba. Actualmente realiza el Doctorado en Letras en la misma institución. Investiga la relación entre literatura y visualidad. Llevó adelante, junto a Paula La Rocca, la compilación del libro Figuras de la intemperie. Panorámicas de estéticas contemporáneas (Editorial UNC, 2019).

ana.neuburger@gmail.com

iDhttps://orcid.org/0000-00023357-7645

* Artículo de reflexión. El presente artículo se enmarca en la tesis doctoral en curso titulada "Tiempo, imagen y escritura en la literatura argentina contemporánea" en la Universidad Nacional de Córdoba, Facultad de Filosofía y Humanidades, Doctorado en Letras. Este doctorado es financiado con una beca de CONICET. 


\title{
The Present and its Remaining Art, Literature and Image in the Contemporary Aesthetics
}

\begin{abstract}
In the last decades, the field of aesthetics and the studies on art have participated in a series of transformations and movements that brought together two issues: the announcements about the end of art (and even more broadly, the end of meaning, of history, literature) and the debates on the post-autonomy of art. Based on the critical and theoretical contributions of Nelly Richard, Jacques Rancière, Giorgio Agamben, among others, this article explores the emergence of the notion of image in the contemporary scenario in order to point out the senses that advocate the expiration of art or, its opposite, an impulse of innovation of the forms. Faced with the opening of the relationship between art and literature, this displacement is possible to read in the way that contemporary Argentine criticism composes a constellation of meanings between image, writing and the present.
\end{abstract}

Key Words: Contemporary Aesthetics; Literary Criticism; Image; Jacques Rancière;Post-autonomy. 
Sobre el fin del arte y los debates de la postautonomía

$$
\begin{array}{r}
\text { ¿Qué produce un presente } \\
\text { como diferente } \\
\text { y cómo un presente enfoca } \\
\text { a su vez un pasado? } \\
\text { Hal Foster }
\end{array}
$$

Una serie de interrogantes y posicionamientos conforman el horizonte de pensamiento de nuestra época, allí donde las condiciones límites de las prácticas artísticas se tornan, al menos, problemáticas. Aquello denominado fronteras del arte abrió una zona especialmente productiva para repensar e insistir sobre qué cuestiones ocupan lugar en el campo del arte. El debate, sabemos, es extenso y complejo y, por tanto, no intentaremos reconstruir ni historizar el rumbo variable que tomó la estética en el curso del tiempo. Antes bien, nos interesa recuperar discusiones que surgen propiamente del campo estético, que modulan y constituyen aquello que entendemos como tiempo presente. Buscaremos entonces entablar algunas relaciones conceptuales y críticas que intervienen e inciden de manera directa en el escenario contemporáneo de las problemáticas estéticas. No obstante, estas indicaciones o delimitaciones tampoco reducen la complejidad y vastedad de la cuestión. Por lo tanto, quisiéramos reparar en un aspecto que advertimos presente en mu- chas producciones contemporáneas, materiales estéticos que manifiestan, abordan, y problematizan el vínculo entre escritura e imagen.

Los estudios en torno a la autonomía del arte constituyen en nuestros días un amplio y prolífico campo de discusión, en la medida, en que cada época se ha ocupado de discutir los alcances de aquello que en términos de especificidad/inespecificidad otorga sentido a las prácticas estéticas. Quizá nuestro tiempo hace propia dicha discusión en un escenario estético, político, filosófico que desde hace varias décadas se piensa, al menos, en términos de agotamiento. La clausura, en tanto diagnóstico de época, se infiltró no sólo en el campo de la filosofía o la historia, sino, aún más, en lo que refiere a la producción artística. Dice Nelly Richard al respecto, que: "Las rupturas y los estallidos de la modernidad occidental hicieron que esas fronteras de delimitaciones, de especificidad artística se conviertan en una zona de roces y fricciones entre la autonomía (separación, distancia) y la heteronomía del arte (mezclas, revolturas)" (Richard, 2014, p. 10). La tensión entre ambos términos, y el lugar de disputa que ocupó históricamente la idea de frontera, hicieron que aquello que denominamos fronteras del arte asumiera la forma de un borde incierto, una zona de cruces "que tornaron híbridas tanto las categorías estéticas como las operaciones artísticas" (Richard, 2014, p. 10). Si la frontera actúa, en la lectura de Richard, como una zona permeable y a la vez diferencial, entonces la histórica figuración del límite, de línea que decide incluir o finalmente separar, se tornó no sólo inestable en las últimas décadas, sino también, temporalmente móvil en lo que refiere al trazado histórico.

Esto ocurre, además, en un contexto de crisis del discurso de la estética que asumió para sí un sintagma de gran peso: el fin del arte. Quizás, el último gran impulso de innovación que trajeron consigo las vanguardias tomó la forma de un pensamiento nostálgico que reclama aún un sentido perdido. De este modo, lo enuncia Rancière:

\section{La manera en que "la estéti- ca", ha llegado a ser en los últimos veinte años, el lugar privilegiado en el cual la tra- dición del pensamiento críti- co se ha metamorfoseado en pensamiento del duelo. [...] Así, el pensamiento del arte se convertía en el lugar en el que se prolongaba, luego de la proclamación del fin de las utopías políticas, una drama- turgia del abismo originario del pensamiento y del desas- tre de su desconocimiento. (Rancière, 2009, p. 6)}

Las derivas que llevaron a proclamar el fin del arte, en términos de una pérdida de sin- 
gularidad de la obra de arte, conducían a reflexionar sobre los límites de la esfera artística en los términos de inclusión y exclusión. El cuestionamiento generalizado que anunció el fin de la estética - en el marco de la caída de los grandes relatos que tramaban los sentidos a partir de los cuales se configuraba el mundo (la historia, la experiencia, el sentido, la literatura) - 1 encontró en el tono nihilista un sostén a partir del cual obturar de algún modo la discusión. En otras palabras, frente al diagnóstico de agotamiento se volvió inoperante además el marco de inteligibilidad de las producciones estéticas y los modos de lectura y crítica posibles.
Sin embargo, quisiéramos trazar un recorrido teórico en el que es posible advertir un desplazamiento ante la mirada nostálgica y decadente sobre el fin. Una serie de pensadores, entre los cuales podemos destacar a Georges Didi-Huberman y Jacques Rancière, tomaron ese mismo marco de inteligibilidad que anunciaba el agotamiento del sentido para volverlo condición misma de un hacer. Un hacer pese a todo (Didi-Huberman, 2015). Los anuncios del fin encuentran en estos autores la emergencia de una crisis, pero tomada como punto de partida, donde es posible, a su vez, avizorar la emergencia de una nueva potencia. De este modo, el escenario contemporáneo signado por ruinas de sen- tidos, ahora inoperantes, suspende el pensamiento de duelo para hacer de esos restos la posibilidad misma de interrogación por el presente. Condición paradójica, puesto que la línea de pensamiento de estos autores se afirma en la ruptura del entramado de sentido que se imponía hace un siglo atrás, a la vez que anuncia y relanza la posibilidad de producción de sentido en el presente. Estas lecturas asumen un estado de copertenencia entre ambas posiciones, un doble movimiento histórico "entre el diagnóstico de un retiro de lo contemporáneo y un pensamiento de los posibles re-trazos del mismo" (Maccioni, 2017, p. 7), que de modo subrepticio podemos encontrar en algunos libros de Didi-Huberman, como

Nelly Richard en diálogo con Ticio Escobar piensa el debilitamiento de la autonomía del campo artístico en el contexto de una crisis que comienza a registrarse desde el auge de las industrias culturales y la apertura del predominio de lo visual: "Este entrecruzamiento de las fronteras del arte ocurrió bajo los efectos del capitalismo cultural que, con su masivo reparto de iconografías y guiones de consumo, pone la visualidad al servicio de los dispositivos de exhibición-circulación de las imágenes que las distribuyen culturalmente como formas-mercancías. Este nuevo universo de la cultura visual [...] llevó a la esfera artística a preguntarse defensivamente - por la vigencia de las fronteras que, en la tradición, realzaban las obras y los estilos en tanto objetos de estudio privilegiados y exclusivos de la historia del arte que se cuidaba de diferenciarlos del resto de los artefactos visuales comúnmente difundidos por las industrias de las imágenes" (2014, pp. 11-12). Richard lee las transformaciones de la esfera artística de la mano del campo de la visualidad en expansión. Quizás podríamos terminar de componer el escenario de la crisis de la autonomía del arte en el marco generalizado de una crisis del discurso filosófico (pérdida de la experiencia, del sentido, del tiempo histórico) la cual adopta durante un tiempo el tono nihilista como fundamento de la clausura y el agotamiento. 
un recomenzar ${ }^{2}$ lo ya dado, descentrando toda idea de origen y otorgando al presente nuevos alcances. Al respecto, escribe Agamben en Idea de la prosa (1989): “

Como si más allá de esta alternativa no existiese la única probabilidad propiamente humana y espiritual: la de sobrevivir a la extinción, de saltarse el fin del tiempo y de las épocas históricas, no hacia el futuro y el pasado, sino hacia el corazón mismo del tiempo y de la historia. (Agamben, 1989 , p. 70
Salvar la época de su propia concepción de época. Agamben insiste en hacer uso de la potencia de nuestro tiempo, sólo allí donde se abre la posibilidad de detener su curso y dar lugar a lo contemporáneo (Agamben, 2014). Acaso esta idea de decadencia contenga en su interior una cuestión más determinante aún: el sentido progresivo, causal y homogéneo del tiempo histórico. No quisiéramos detenernos demasiado en esta cuestión, sí, al menos, señalar el camino decisivo que abrió Walter Benjamin con las tesis Sobre el concepto de historia (2009), al perturbar la linealidad homogénea de la historia y dotar al presente de otros alcances temporales: anacronismos, latencias, irrupciones, discontinuidades ${ }^{3}$.

Consignado, entonces, el agotamiento del "cuestionamiento radical acometido por la vanguardia" (Oyarzún, 2015, p. 65), se abrió un panorama que se encargó de disputar los límites, los soportes y los marcos de las prácticas artísticas, panorama que configura nuestro modo sensible de lo contemporáneo.

Acaso esta idea de recomenzar el tiempo histórico se halle con más potencia en Supervivencia de las luciérnagas (2012), en el que Didi-Huberman, a propósito del diagnóstico fúnebre que supo enunciar Pier Paolo Pasolini, alce su mirada no ya hacia los grandes reflectores del espectáculo, ni hacia la oscuridad decadente del fin del sentido, sino, más bien, hacia esas luces menores, luciérnagas, como modo de una apuesta por lo menor, por un comienzo en lo ya hecho. También puede rastrearse dicha noción en La imagen superviviente. Historia del arte y tiempo de los fantasmas según Aby Warburg (2009), donde Didi-Huberman realiza un estudio minucioso del término nachleben a partir de la figura olvidada de Aby Warburg, abriendo el tiempo histórico ante la presencia de latencias, síntomas e irrupciones. En este punto, se condensan precisamente dos líneas fuertemente significativas de la lectura benjaminiana de Didi-Huberman: el psicoanálisis y las vanguardias. Por último, nos remitimos especialmente, para un estudio y seguimiento de la noción de recomienzo, al libro Hacer. Ensayos sobre el recomenzar (2015), compilado por Javier Martínez Ramacciotti y Franca Maccioni, y a la tesis doctoral de Franca Maccioni Contemporáneos del mundo: políticas de la imagen y del recomenzar en la obra de Joaquín O. Giannuzzi (1924 - 2004) y en otros poetas argentinos (2017).

El sentido del tiempo histórico, bajo el dominio de la idea de progreso, percibe en el curso del tiempo una finalidad determinada, un punto hacia dónde dirigirse. Y comprende la explicación de los hechos acontecidos de la historia bajo la lógica de la causalidad. El tiempo histórico, en términos de progreso, asume el riesgo de configurar una temporalidad homogénea en la que la lectura de los hechos del pasado -en tanto continuidadsirven como simple comprobación de un fin ya dado en la historia. Un sentido de la historia ya escrito donde los acontecimientos sucedidos sólo confirmarían una finalidad próxima a realizarse, en el que la historia ya determinó sus propias condiciones de existencia. Comprender los hechos del pasado como objetos inertes capaces de ser aislados y dispuestos en un relato histórico no contempla el movimiento del que está hecho la historia. El pensamiento de Benjamin posibilita, a partir de una crítica a la teoría del progreso, un acercamiento a un modo diferente de pensar la temporalidad, una apertura histórica. Permite ver irrupciones en el curso de las cosas donde sólo había una línea marcada por causas y efectos. Desde allí, la relación con lo que ha sido es siempre una relación de actualización, un momento crítico que el presente le hace al pasado. Consignamos a continuación los escritos que se destacan en el tratamiento de esta problemática: La dialéctica en suspenso. Fragmentos sobre la historia (2009), edición a cargo de Pablo Oyarzún que reúne una serie de ensayos de Benjamin entre los que se encuentra Sobre el concepto de historia, las célebres tesis de la producción tardía del autor; El libro de los pasajes (2005), en especial el convoluto N "Teoría del conocimiento, teoría del progreso" donde la suspensión del tiempo histórico es inseparable del acontecer de la imagen dialéctica. 
En este sentido, si partimos de una revisión de los discursos que abogan por la crisis total de la producción estética (que a su vez se fundan sobre la base de un pensamiento del tiempo como continuum progresivo y lineal), esto no conduce inevitablemente hacia una reivindicación de cierto impulso vanguardista que proclama aún la innovación de las formas. Dicha posición adopta la configuración del arte en términos de ruptura/novedad, producto de la disolución de las fronteras que custodiaban la autonomía estética y, en consecuencia, constituye también un presente pleno de novedad. Antes bien, quisiéramos pensar una copertenencia entre la crisis - aquello que ya no opera en el sentido presente- y la apertura a la reactivación de nuevas potencias, para entablar otra relación estética y política con el tiempo y con la historia:

Un nuevo uso que no repite sin más lo previamente interrumpido ni busca originar una novedad radical, sino que se lanza a ensayar modos de recomenzar otras praxis del sentido, otras relaciones contemporáneas con la historia y modos inéditos de recomenzar la creación y simbolización del mundo al interior de este horizonte finito. (Maccioni, 2017, p. 7)

Asumir el fin del arte como tal, significa, en primer término, concederle a la historia un sentido lineal, teleológico y, por tanto, decadente. Y, además, signa nuestro presente en términos de pura novedad, como consecuencia de un estadio anterior de ruptura.

En esta estela, piensa Miguel Dalmaroni el problema de la literatura en el marco de esta crisis generalizada: "Lo erróneo es el modo mismo de la frase ya no se puede, porque rinde tributo a una concepción plana, lineal, cronologista del tiempo, $\mathrm{y}$, a veces, a una concepción periodicista del tiempo de la experiencia" (Dalmaroni, 2010, p. 1). No intentaremos, frente a la decadencia, reivindicar el impulso vanguardista de la innovación. Más bien, sostenemos que es al interior mismo del diagnóstico generalizado del fin del tiempo y de la historia que debemos articular y retrazar nuevos modos contemporáneos de las prácticas estéticas. $\mathrm{O}$, como expresa Rancière "un trabajo a largo plazo que apunta a restablecer las condiciones de inteligibilidad de un debate" (Rancière, 2009, p. 7). Habitar, entonces, el paisaje propio de esas ruinas y precisamente desde allí interrogar los modos de enunciación del presente.

En este sentido, resulta conveniente recuperar aquello que Rancière entiende por régimen estético del arte. Primero, porque habilita una lectura de los materiales estéticos de la actualidad que no recae en el historicismo de las formas en términos de rupturas y progresos, según un relato que opera por excepción y refundación de nuevos proyectos. Si desistimos de otorgar a nuestro tiempo el carácter radical de lo nuevo o su reverso, de agotamiento, quizás podamos advertir un desplazamiento en lo que refiere al campo de las artes. Este deslizamiento supone exponer el estado de crisis y, a su vez, las posibles reconfiguraciones (o repartos, en los términos del autor) que de él emergen. Además, porque dicho movimiento permite una lectura de los conceptos propios del presente debate no en términos de un sentido otorgado a priori sino modulados por determinaciones históricas y temporales. Rancière parte de la distinción de tres regímenes de identificación de las artes -ético, representativo y estético- pero no como el resultado de fases basadas en evoluciones y rupturas de unos con otros, sino, más bien, como movimientos que tiene lugar al interior de las prácticas artísticas.

En otras palabras, los regímenes conviven históricamente, otorgan modos de figuración de las artes, sólo que cada uno aporta un marco de inteligibilidad diferente. No responden a la periodicidad del trazado histórico, como si a cada época le correspondiera la lectura de un régimen específico de identidad del arte. Si bien su emergencia 
puede ser historizada, esto no es resultado de una correlación sucesiva. Por el contrario, los diferentes regímenes coexisten en el presente. Quizás la intervención de Rancière, en este debate, desencantando sobre el rumbo de la estética tenga más que ver con el aporte de un nuevo marco de inteligibilidad ante eso incierto que se nos presenta cada vez bajo el nombre de prácticas artísticas. Escribe a propósito del régimen estético:

El régimen estético de las artes es el que propiamente identifica el arte con lo singular y desliga a este arte de toda regla específica, de toda jerarquía de los temas, de los géneros y de las artes. Pero lo realiza haciendo estallar en pedazos la barrera mimética que distinguían las maneras de hacer del arte de otras maneras de hacer y separaba sus reglas del orden de ocupaciones sociales. Afirma la absoluta singularidad del arte y destruye al mismo tiempo todo criterio pragmático de estas singularidades. (Rancière, 2009, p. 26)

El régimen estético no emerge como resultado de las rupturas fundamentales en el seno de la historia de las artes, ya que, esa historia de sucesión de estados, de grandeza y decadencia, se ha diluido. Puesto que, al interior mismo de este régimen convive la expresión y manifestación de temporalidades heterogéneas.
Convoca un régimen nuevo de la relación con lo antiguo que "se consagra a la invención de nuevas formas de vida sobre la base de una idea de lo que el arte fue, ha sido" (Rancière, 2009, p. 28). A partir de la lectura del autor, podemos decir que habría que distinguir aquí dos sentidos opuestos de historicidad.

La separación de lo antiguo y lo moderno cobra sentido al interior del régimen representativo, pero desde el régimen estético de las artes, esas formas de ruptura caen para dar lugar a la convivencia de formas heterogéneas del tiempo, donde el presente no deja de poner en escena el pasado.

La separación de un dominio puro del arte, desde el marco de inteligibilidad que abre el régimen estético, se tornó inestable en la actualidad. Puesto que la forma se libera de su determinación histórica para afirmar su propia historicidad y con ella una historia propia de la forma misma.

Cuestionado el diagnóstico del fin como clausura del sentido y de la producción, Rancière traza un ligero, pero significativo desvío: no ya el agotamiento de las formas, tampoco la mera celebración de lo fragmentario, sino una proliferación de "la capacidad de toda materia para convertirse en forma y tema" (Rancière, 2011 p. 71).
Imagen, temporalidad y escritura

Y puesto que es en la imaginación donde algo como la historia se ha hecho posible, es también en la imaginación donde ésta debe decidirse de nuevo una y otra vez

Giorgio Agamben

La cuestión de la imagen en la contemporaneidad se ha tornado un problema, un tema y una operación crítica al momento de constatar su aparición en el campo de la literatura y constituye su presencia un cambio en el imaginario estético contemporáneo. A partir del vínculo que se abre entre palabra e imagen es posible redefinir de algún modo la articulación entre literatura y otras prácticas artísticas (el cine, las artes visuales, la fotografía, etc.). Como expresa Rancière en $\mathrm{El}$ destino de las imágenes (2011): "el propio concepto de 'imagen' [...] aparece como una operatividad metamórfica, atravesando las fronteras del arte y negando la especificidad de los materiales" (p. 59).

Desde esta perspectiva, la imagen se constituye como un operador crítico capaz de entablar una relación contemporánea con el tiempo. Esto significa, siguiendo la propuesta de Didi-Huberman (2011), que la imagen es portadora de tiempo, de todo aquello en lo que un 
instante del pasado y un instante del presente se unen en una constelación. La lectura de Benjamin, en este punto, se vuelve ineludible. Si decimos que la imagen tiene lugar en el encuentro de tiempos múltiples (esto último en plena consonancia con la lectura a contrapelo benjaminiana) advertimos allí, en la ocasión de ese choque, un reconocimiento que habilita la lectura de dicho movimiento. Es lo que Benjamin plantea en términos de: el ahora de la cognoscibilidad, el punto crítico en el que emerge toda legibilidad. Podríamos mencionar una serie de autores que comparten una estela de pensamiento alrededor de estas ideas; quisiéramos mejor recuperar en un primer momento las lecturas de Georges Didi-Huberman y Giorgio Agamben, en tanto que, ambas han asumido en nuestros días no sólo la tarea de volver actual el pensamiento de Benjamin (Neuburger, 2015), sino también, destacar el lugar central que ocupó la reflexión sobre la imagen en muchos de sus escritos.
En Agamben, la pregunta por lo contemporáneo y por el lugar que ocupan las imágenes en ese horizonte presente convergen en la necesidad de detener el curso incesante de la historia para dar lugar a un tiempo interrumpido, desfasado, intempestivo $^{4}$. Ser contemporáneos es habitar la cesura, el punto de fractura donde los diferentes tiempos se encuentran. Precisamente allí tiene lugar la emergencia de la imagen, en el punto oscilante entre la detención y el movimiento. El autor italiano recupera la noción de dialéctica en suspenso de Benjamin para pensar la imagen en el horizonte de lo contemporáneo. Ésta acontece en un umbral, en tanto, dicha suspensión no afirma la pura detención que luego reanudará el movimiento, sino que, la ocasión de apertura de la imagen consiste en "una pausa cargada de ambas tensiones" (Agamben, 2010, p. 30). Ambos elementos coexisten en ese instante de tensiones polares, en el que "el medio queda expuesto como zona indiferenciada [...] entre los dos términos opuestos" (Agamben, 2010, p. 31). La imagen, en este sentido, se constituye siempre a través de una red sucesiva de remisiones temporales y da lugar a la legibilidad que la remite al presente. Un presente que se encuentra siempre escindido.

La propuesta del filósofo italiano condensa una imagen que rechaza cabalmente la conceptualización en términos de apariencia estética, sino que, supone un complejo anudamiento de tiempos en el que el pasado, antes que se agote, resguarda la emergencia de las virtualidades latentes de lo aún incumplido. Toda imagen es la ocasión de apertura de ese desplazamiento temporal y reclama para sí una experiencia del tiempo que interrumpe las narrativas lineales y homogéneas.

Por su parte, la lectura que realiza Didi-Huberman, acerca del debate en torno al fin de la historia y del arte, lo condujo a explorar una reformulación del tiempo histórico inherente de un pensamiento sobre la imagen. En la articulación de tiempo e imagen, la presencia de Walter Benjamin se torna ineludible, así también, la recuperación de

${ }_{4}$ El vínculo que une a ambos pensadores a un primer momento resulta evidente: Agamben emprendió la tarea de editar la obra de Benjamin al italiano. Quizás, el lazo más indiscutible y fuertemente trabajado sea la serie que inicia con Homo sacer, de marcada impronta benjaminiana, además del renombrado ensayo sobre la destrucción de la experiencia. Quisiéramos, desde otro lugar, postular ciertos reenvíos presentes en otros escritos del filósofo italiano, en los cuales no podemos dejar de evidenciar una importante lectura de Benjamin en torno a las cuestiones que atañen a la temporalidad y a la imagen (ensayos más breves como los que conforman Ninfas, Desnudez, Idea de la prosa). Y con esto, quisiéramos aclarar que no iniciamos una búsqueda hacia aquellos textos que trabajan explícitamente nociones de Benjamin en la obra de Agamben. Más bien, nos interesa rastrear ese gesto benjaminiano, propio de un modo singular de pensamiento sobre la imagen y la historia, de un trabajo dialéctico al interior de los conceptos. 
la figura de Aby Warburg y los modos de supervivencias de la historia. En primera instancia, el diagnóstico de agotamiento asume, como mencionamos, una visión del tiempo histórico homogénea, lineal y progresiva. En Didi-Huberman dicho desplazamiento hace emerger tiempo anacrónico, en tanto que será "el modo temporal de expresar la exuberancia, la complejidad, la sobredeterminación de las imágenes" (Didi-Huberman, 2011, p. 39). Plantear la cuestión del anacronismo conlleva precisamente a dotar el tiempo de cierta plasticidad desde la que es posible advertir la heterogeneidad de tiempos que operan en cada imagen. Allí, donde el pasado como hecho consumado es interrogado para dar lugar a retornos intempestivos, discontinuidades y tiempos incumplidos se da la ocasión y apertura de una temporalidad anacrónica para la historia. Asimismo, allí también es donde se conforma el pliegue, dirá el autor, del vínculo entre tiempo e imagen, emerge el anacronismo.

En este sentido, la imagen no es un "simple soporte de iconografia" (Didi-Huberman, 2011, p. 71), sino, que configura una operación crítica al interior de dos tendencias fundamentales en la obra del autor: la lectura psicoanalítica del síntoma y la lectura de la historia a contrapelo de las vanguardias. El pensamiento de la imagen como centro turbulento de la práctica histórica emerge en el punto de encuentro de estas tendencias. Escribe Didi-Huberman a propósito de Benjamin:

La imagen no está en la historia como un punto sobre una línea. La imagen no es ni un simple acontecimiento en el devenir histórico ni un bloque de eternidad insensible a las condiciones de ese devenir. Posee - - o más bien produce - una temporalidad de doble faz -[...] Benjamin terminó de captarlo en términos de 'dialéctica' y de 'imagen dialéctica'. (2011, p. 143)

El doble movimiento que convoca la imagen constituye el desplazamiento propicio para no leer en ella sólo un documento de la historia, sino eso que el filósofo alemán formuló en términos de imagen dialéctica, esto es, el anudamiento y punto de encuentro de lo visual y lo temporal, el instante en el que se reúnen y chocan un trozo del pasado y el ahora. "La imagen no es la imitación de las cosas, sino el intervalo hecho visible, la línea de fractura de las cosas" (Didi-Huberman, 2011, p. 166). Tanto Agamben como Didi-Huberman parecen coincidir en la lectura benjaminiana de la cesura como acontecer de la imagen, del paradójico movimiento que otorga un lazo (relación), a la vez, que produce una hendidura (interrupción) $\mathrm{y}$, al mismo tiempo, abre así un campo lleno de tensiones. Dicha suspensión no es pensada en términos de un detenimiento pleno, sino que "hace emerger un contrarritmo, un ritmo de tiempos heterogéneos sincopando el ritmo de la historia" (Didi-Huberman, 2011, p. 171). El montaje en Didi-Huberman convoca una operación próxima al movimiento de la interrupción, una doble articulación del procedimiento que supone en principio un desmontaje, una separación de los elementos que la componen para luego remontar esas piezas, recomponer sus sentidos. Esta operación no sólo custodia la visualidad de una constelación de sentidos, sino que, además, asegura su propia legibilidad.

En la línea de esta propuesta, Eduardo Cadava se propone recuperar también la figura de Benjamin, pero no sólo la reflexión teórica en torno a la imagen que suscita su pensamiento, sino, que está en concomitancia al lugar decisivo que ocupó en relación con su escritura. En Trazos de luz. Tesis sobre la fotografia de la historia (2014), el autor establece un recorrido por las principales nociones de Benjamin (historia, despertar, mímesis, inscripciones, relámpagos, peligro, lenguaje, semejanzas) que se encuentran atravesadas por la singular relación entre palabra e imagen. Partiendo de la tesis como "modo privilegiado de representación en Benjamin" (Cadava, 2014, 
p. 24), el autor sostiene que el pensamiento benjaminiano - principalmente, el modo de concebir la historia, signado por un estado de detención- se encuentra acompañado por una escritura entendida como modo de inscripción de ese paradójico movimiento. De allí deriva el carácter plástico de sus escritos:

Como las fotografías aéreas de Nadar, la escritura de Benjamin pretende capturar el mundo que se agita bajo su mirada, utilizando un campo de imágenes huidizas cuyas ruinas nombran la relación esencial que la fotografía entabla con la muerte. En lo que sigue, sugiero que el carácter visual que late en el corazón del estilo de la escritura y del pensamiento benjaminiano este Bildlichkeit fotográficoestá vinculado a su esfuerzo por postular la cuestión de la imagen como centro pro- blemático de la modernidad. (Cadava, 2014, p. 27)

Trazos de luz afirma que la imagen se cristaliza en la escritura en al menos dos sentidos. Por un lado, en su carácter fragmentario, próximo al aforismo en algunas ocasiones, marcado principalmente por la interrupción y la discontinuidad. La capacidad de contraer el movimiento de la historia se despliega en una escritura que se detiene, interrumpe y reescribe. En este sentido, la suspensión de la continuidad temporal provee a la historia de una figuración que Benjamin nombra constelación. Por otro lado, la afinidad entre imagen y escritura se asocia, en el filósofo alemán, en el uso de un lenguaje notoriamente plástico a partir de la presencia insistente de una serie de figuras. A través de las imágenes del relámpago, el centelleo, el torbellino, Ben- jamin ensaya una y otra vez los modos de desmontar la barrera establecida entre escritura e imagen, punto que Cadava lee como gesto que funda dicho vínculo a partir de un abordaje sobre la técnica fotográfica y su relación con la luz. De este modo, el pensamiento benjaminiano se encuentra marcado por un movimiento concebido como "la apertura de una cámara que entrega sus imágenes" (Cadava, 2014, p. 19). Así, la escritura constituye una superficie de inscripción capaz de fijar el movimiento de las imágenes. Las piezas que componen los escritos de Benjamin son leídas por el autor como "instantáneas en prosa" (Cadava, 2014, p. 22), expresión que confirma nuevamente el cruce entre fotografía y escritura ${ }^{5}$.

Por último, si destacamos el carácter disruptivo de la ima-

Podemos decir que un pensar en imágenes es lo que define primeramente a esta reflexión. Sigrid Weigel (1999) también profundiza en este aspecto de la obra de Benjamin: "Lo específico de la configuración benjaminiana se halla, más bien, justamente en este pensar en imágenes, en la referencia a esas figuras en la que se presenta la realidad y se forja una tradición de imágenes de la historia" (p. 12). Afirma también, a propósito del vínculo entre imagen y escritura: "Sus imágenes de pensamiento son como imágenes dialécticas pero escritas; más precisamente: constelaciones que literalmente han devenido escritura, en las que se desarrolla y se hace visible la dialéctica de imagen y pensamiento" (Weigel, 1999, p. 12). En este sentido, la especificidad del pensar en imágenes, como aspecto diferenciado de la configuración teórica de Benjamin, radica en un modo de pensamiento que no es metafórico o retórico: "las imágenes no son objeto, sino medio y matriz de su concepción teórica" (p. 14). Más bien, sugiere la autora, es "un modo de llevar adelante una reflexión filosófica que coloca fuera de juego al propio discurso filosófico considerado como metadiscurso" (p. 38). La imagen entendida no como suplemento que acompaña la reflexión, ni copia capaz de ser traducida a través de conceptos filosóficos, sino que adquiere "una constelación poseedora de una similitud heterónoma y heterogénea en las que las figuras del pensamiento se amalgaman con las de la historia" (pp. 11-12). En definitiva, las lecturas de Cadava y Weigel sobre Benjamin sostienen que el pensamiento toma forma en la imagen, por la imagen. Es decir, asume el desarrollo de un pensamiento -reflexión teórica en Benjamin-, pero, además, adquiere una manifestación en la escritura (el caso de las imágenes-pensamiento o figuras del pensamiento que propone Weigel), conformando así un movimiento dialéctico que hace de la imagen un término indisociable entre el pensamiento y la escritura. 
gen que señalan los recorridos de estos pensadores, quizás la figura de Rancière ilumine otra zona reflexiva y aporte nuevos indicadores para abrir un posible vínculo entre palabra e imagen. Ante todo, primero advertir un salto en este trayecto: si en Agamben y Didi-Huberman, como también en Cadava, asistíamos a la fuerte presencia del pensamiento benjaminiano en relación con la temporalidad y la imagen, aquí Rancière traza efectivamente otro itinerario. No buscamos sugerir ciertas afinidades en la estela de estos pensadores, sino, más bien, despuntar un territorio problemático común que invita a reflexionar la amplia y compleja noción de imagen: en primer lugar, la de su determinación histórica y, en segundo, la reformulación de lo visible y su articulación con lo decible.

En El destino de las imágenes (2011), la imagen supone la apertura hacia una nueva dimensión de lo artístico en la cual coexisten las operaciones del arte, las formas de la imaginería y el discurso crítico. En el régimen estético, la imagen ya no se erige como la expresión codificada de un pensamiento, tampoco como el doble de una cosa, ni como simulacro que se opone a lo real, sino que es "la manera en que las cosas mismas hablan y se callan" (Rancière, 2011, p. 34). La imagen se sitúa en un régimen que "hace pasar la imagen en la palabra, la pala- bra en la pincelada, la pincelada en la vibración de la luz o del movimiento" (Rancière, 2011, p. 61), desmontando el dominio exclusivo de la presencia visual. La denominada frase-imagen propone un giro decisivo en el vínculo palabra-imagen puesto que la frase ya no abarca exclusivamente lo decible y la imagen, tampoco pertenece al campo predominante de lo visible. Dicha noción produce un desplazamiento entre lo decible y lo visible que descompone la relación representativa entre imagen y texto, y adquiere una doble función en tanto la palabra encadena y la imagen interrumpe.

La frase-imagen compone así una unidad marcada por una potencia de continuidad y, a la vez, por una potencia de ruptura. Tal movimiento conduce a Rancière a pensarla en términos de montaje, próximo al planteo de Didi-Huberman, puesto que configura un encuentro de heterogeneidades que aloja en su interior una dialéctica de lo diferente, cuya oscilación se sostiene entre la cercanía y la distancia de sus elementos. En palabras de Rancière:

Se trata de organizar un choque, de poner en escena una extrañeza de lo familiar, para hacer aparecer otro orden de medida que sólo se descubre mediante la violencia de un conflicto. La potencia de la frase-imagen que une las heterogeneidades es entonces la de la separación y el choque que revela el secreto de un mundo, es decir, el otro mundo cuya ley se impone detrás de sus apariencias anodinas o gloriosas. (Rancière, 2011, p. 72)

La frase-imagen otorga así un nuevo marco de inteligibilidad cuyo movimiento traza, por un lado, el disenso, la separación, la interrupción; por el otro, la continuidad, el encadenamiento: la imagen es entendida allí como "la potencia vinculante de lo desvinculado", (Rancière, 2011, p. 74). Precisamente, por esto es que el autor compone el sintagma que reúne palabra e imagen, ya que del dominio de lo puramente visual no convoca la emergencia de una potencia relacional que reúne y asocia aquello que no estaba destinado a hacerlo.

Por tal motivo, cuestiona la especificidad que pueda hallarse en el arte cinematográfico o en la fotografía, puesto que las condiciones técnicas no garantizan su autonomía en relación con las demás prácticas. Ante la diversidad de soportes que puedan presentar dichas prácticas, Rancière inaugura otro modo de "articulación entre prácticas, formas de visibilidad y modos de inteligibilidad" (Rancière, 2011, p. 89) que resguarda la auténtica posibilidad de una relación entre "el arte de las palabras y el arte de las formas" (Rancière, 2011, p. 91). 


\section{Literatura, imágenes y pre-} sente

Toda literatura aspira a la condición

de arte contemporáneo

REINALDO LADDAGA

La cuestión de la imagen en la literatura argentina de las últimas décadas produjo un efecto sensible que se tradujo en la preocupación por ensayar modos de exhibición y mostración del tiempo presente. Imagen y escritura conformaron así una constelación decidida a explorar las formas de lo contemporáneo, a partir de un pensamiento sensible del propio presente. Luz Horne lee este desplazamiento en el imaginario estético como un modo renovado de las formas de representación que buscan construir un "retrato de época" (2011, p. 15). En el marco del fin de las vanguardias y el agotamiento de sus propuestas estéticas, la literatura contemporánea ocupó también un lugar destacado en las diversas modulaciones sobre el fin, en consonancia con los debates sobre la autonomía del arte que desarrollamos anteriormente. En este punto, no podemos dejar de mencionar los aportes de Josefina Ludmer $(2007,2010)$ los cuales conformaron la apertura de la problemática en Argentina para reflexionar sobre las escrituras del presente, en términos de literaturas postautónomas, esto es, escrituras que atraviesan sus fronteras ante la pregun- ta por el estatus de lo literario y difuminan las barreras que separaban la ficción de la realidad. Según Ludmer, la literatura a partir del año 2000 se instala en "un régimen de significación ambivalente" (2007, s/n). Entre los diversos diagnósticos del fin de la autonomía, Marcelo Topuzian señala el desplazamiento del sentido trágico y decadente propio de la modernidad, hacia la nueva potencia que abre el escenario contemporáneo "sin imaginación dramática alguna del fin" (2013, p. 319). De este modo, se manifiesta un mayor énfasis en señalar "las mutaciones, estados, condiciones y derivas recientes de la literatura y las artes en lo que sería el después del fin de la literatura y del arte" (Dalmaroni, 2016, s/n).

Recuperamos la figura de Ludmer porque desde allí se configuró, en el ámbito académico y de la crítica literaria argentina, el lugar paradigmático sobre el que se enunció y discutió el tan mentado fin de la literatura. Aquí América Latina (2010) alcanzó una considerable resonancia en ese contexto, indicando un modo de leer ciertos materiales estéticos al fragor del año 2000 como temporalidad ejemplar de todo tipo de ruptura. Se le ha concedido un gesto de radicalidad y novedad quizás por el tipo de escritura que despliega, señalada en términos de una deriva estética en sus escritos, más próxima al diario y la bitácora, en un intento por marcar una distancia de cierta crítica académica a pesar de los temas que allí convoca. Ludmer plantea el borramiento de una serie de oposiciones binarias tales como: realidad-ficción, individual-social o afuera-adentro, oposiciones que parecieran venir del tiempo oscuro de la autonomía y dicho borramiento parece ser saldado a partir de lo que la autora denomina la ficción especulativa y realidadficción:

La imaginación pública fabrica realidad, pero no tiene índice de realidad, ella misma no diferencia entre la realidad y la ficción. Su régimen es la realidadficción, su lógica el movimiento, la conectividad y la superposición, sobreimpresión y fusión de todo lo visto y oído. Es fuerza creadora de realidad, la materia de la especulación, funciona según muchísimos regímenes de sentido y es ambivalente: puede darse vuelta o usarse en cualquier dirección. (Ludmer, 2010, p. 12)

El problema de la postautonomía se sitúa en este libro como el resultado de una serie de operaciones que las obras realizan en relación con un relato temporal, desligándose de ese propio relato histórico. Lo que se anuncia como el fin de la literatura aparece inscripto en el horizonte final de la era de la autonomía. El problema, pensamos, quizás sea leer el cambio radical que supone ese despla- 
zamiento precisamente en el cambio de milenio cuando, según este recorrido y más aún si pensamos en Rancière, ese movimiento ya podemos detectarlo tiempo atrás (el ejemplo más paradigmático de Rancière es Flaubert). Y no sólo eso: dicha lectura dependerá no de marcar ese punto de inflexión en un año tan auspicioso como el 2000, porque hacerlo significará caer en el riesgo de todo lo que alerta Aquí América Latina: el riesgo de convocar una temporalidad homogénea para leer el presente histórico. Quizás el problema sea asociar, como advierte Miguel Dalmaroni, un modo de leer determinado a un tiempo determinado: "Josefina Ludmer narra haber leído durante el año 2000 como un ciudadano del siglo XIX occidental, dos géneros del siglo XIX occidental: es decir, por la mañana los diarios, por la noche novelas" (Dalmaroni, 2010, p. 3). Desde allí, Ludmer incorpora a su relato una serie de nociones centrales para abordar el arte y la literatura: imaginación, ficción, realidad, entre otras. "Figuras, nociones, tema que de ningún modo conviene tratar como evidencias o liquidar en fórmulas asertivas que no sabemos por qué deberíamos aceptar como axiomas" (Dalmaroni, 2010, p. 4). Dalmaroni sugiere que, si la intención de Aquí América Lati$n a$ es establecer un cierto correlato entre esa temporalidad, que en reiteradas ocasiones nombra en términos de aceleración y ra- pidez propias del tiempo en que vivimos, y la forma más bien experimental que asume la escritura en términos de procedimiento, esa intención no resulta efectiva.

En el campo de la crítica literaria, la cuestión de la autonomía (y los debates en torno a lo post) se tornó central para reflexionar sobre las transformaciones que efectivamente son posibles detectar en la literatura argentina de las últimas décadas. El problema, en todo caso, será desde qué enfoque hacerlo, qué marco de inteligibilidad le daremos a tales lecturas, sin por ello recaer en generalizaciones que advierten, en todo tipo de convivencia de heterogeneidades, el surgimiento de algo inaudito. La manifestación del nuevo mundo que detecta Ludmer, en el año 2000, un mundo aparentemente fundado desde cero, nos situaría otra vez en la compleja zona que planteamos al comienzo: la configuración del arte entendida en términos de ruptura/novedad, asistida siempre por un relato progresivo de los hechos históricos.

Tomamos el libro de Ludmer porque indudablemente allí tiene lugar una apertura significativa para reflexionar sobre las transformaciones que tuvieron lugar en la literatura argentina de las últimas décadas. A partir de esto, podemos destacar que en la actualidad una parte considerable de la crítica litera- ria sostiene la pregunta por las formas de configuración de lo contemporáneo en la literatura y sus procedimientos. El cruce entre literatura y visualidad se tornó una zona de pensamiento y productividad en los debates de la crítica literaria contemporánea del último tiempo. Decimos literatura y visualidad en los términos en que piensa Miguel Dalmaroni (2016), al amplio campo de reflexión que suscita un pensamiento sobre la imagen. La relación de lo visual, lo visible, lo imaginable con la escritura, afirma el crítico, es constitutiva de la literatura misma. Supone un modo de leer el espacio entre que enlaza a la vez que separa ambos términos, para concluir que precisamente la heterogeneidad y la intermitencia caracterizan el vínculo entre literatura y visualidad. En su artículo, el crítico traza un mapa en el que se despliegan los modos en que la literatura tiende lazos y se articula con lo visible y con las artes en general, sin dejar de mencionar que buena parte de la crítica literaria, o del pensamiento escrito sobre la literatura como prefiere llamarla, evita de forma notoria las tradiciones filosóficas sobre la vista, la mirada o la percepción (enmarcadas en el denominado régimen escópico, fuertemente vinculado con el psicoanálisis). De allí, se desprende la hipótesis, a partir de la discontinuidad como modo de relación con lo real, de un vínculo siempre escindi- 
do con lo visible, lo imaginado y lo decible; vínculo que abarca modos de la percepción no sólo estrictamente visual. Del resultado de estas indagaciones, Dalmaroni (2016) insiste en que la crítica literaria argentina actual ha hecho del vínculo entre escritura e imagen la base de un modo de reflexionar sobre lo contemporáneo, a la vez que, da lugar a la conformación de un área de estudios definida por la articulación de la literatura con las artes visuales y con lo visible en general ${ }^{6}$.

El recorrido teórico que iniciamos con Rancière para reflexionar sobre un posible vínculo entre escritura e imagen en el presente significa quizás un desplazamiento, un desvío al menos, ante los reduccionismos temporales que refieren al agotamiento y la novedad para pensar las cuestiones del arte en la actualidad. En nuestro tiempo, resultan incuestionables las transformaciones que tuvieron lugar en el arte y la literatura, y sostenemos allí que el problema principal será en qué marco de inteligibilidad le daremos a tales lecturas; de qué modo produciremos nuevas articulaciones de sentido, para dar lugar a eso que el autor entiende como desacuerdo, para atender la forma en la que el arte interviene produciendo disenso, reorganizando lugares, reinventando sujetos y comunidades. O como leíamos junto a Didi-Huberman, atender a los gestos menores de resistencia que aún persisten en el debate. En ese tipo de apuestas, como a las que apuntan estos autores, quizás encontremos un punto crítico de pensamiento y de lectura del tiempo presente. Pensemos, por último, en el epígrafe de Reinaldo Laddaga de Espectáculos de realidad (2007), en el que se pregunta por el horizonte de expectativa de la literatura. Allí advierte un desplazamiento en el campo de la literatura contemporánea, en el que ciertos escritores de nues- tro tiempo ya no responden al imaginario correspondiente a la larga tradición de las letras, sino que, configuran nuevas zonas de contacto con el arte contemporáneo, es decir, abren un nuevo horizonte en torno a la figura del escritor más próximo al del artista. En este sentido, la imagen puede constituirse como un nuevo operador de sentidos que manifiesta tanto la potencia del presente como su propio estado de crisis y desde allí, quizás, podremos ensayar y articular otros modos de concebir la literatura, la tensión que tiene lugar entre lo visible y lo decible.

Dalmaroni explora el cambio significativo que se da al interior de la crítica literaria argentina: en un primer momento (desde los años 1920 hasta la década de1970) de una impronta fuertemente textualista, acompañada del auge de la lingüística y los estudios del signo, hacia un segundo momento (desde los años 1980 a la actualidad) en el que la visualidad penetra en el pensamiento sobre la literatura. El crítico realiza un recorrido en el que conecta los itinerarios críticos y filosóficos dedicados a la visualidad y la imagen y luego las lecturas que incidieron en la crítica literaria contemporánea, "la biblioteca teórica que circuló en Argentina" (Dalmaroni, 2016, s/n). Fueron decisivos, en este sentido, los textos de Walter Benjamin (2005) y las posteriores lecturas de Didi-Huberman (2008, 2009, 2011), John Berger (2010), Susan Sontag (2006); los de Deleuze sobre el cine (2009, 2022); los de Foucault sobre Magritte (2012); entre otros. De allí que, a partir de estas lecturas, la crítica literaria argentina comenzó a formar una zona de estudios definidos por la visualidad. Entre ellos, Dalmaroni destaca los trabajos de Gonzalo Aguilar (2003) sobre poesía concreta, Paola Cortés Rocca (2011) sobre literatura y fotografía, Florencia Garramuño (2015) y la inespecificidad del arte, Edgardo Laddaga $(2006,2010)$ y Graciela Speranza $(2006,2012)$ sobre las mutaciones del campo artístico, entre muchos otros, quienes en términos más amplios han trabajado la cuestión de la imagen desde múltiples aspectos como la fotografía, la poesía, las artes visuales, la performance, el cine. 


\section{Referencias}

Agamben, G. (1989). Idea de la prosa. Barcelona: Península.

Agamben, G. (2010). Ninfas. Trad. Antonio Gimeno. Valencia: Pre-Textos.

Agamben, G. (2014). Desnudez. Trad. Mercedes Ruvituso y Maria Teresa D’Meza. Buenos Aires: Adriana Hidalgo Editora.

Benjamin, W. (2009a). La dialéctica en suspenso. Fragmentos sobre la historia. Santiago de Chile: LOM Ediciones.

Benjamin, W. (2005). Libro de los pasajes. Madrid: Akal Ediciones.

Cadava, E. (2014). Trazos de luz. Tesis sobre la fotografia de la historia. Trad. Paula Cortés Rocca. Santiago de Chile: Palinodia.

Dalmaroni, M. (2010). Literatura y sus restos (teoría, crítica, filosofía). A propósito de un libro de Ludmer (y de otros tres). Bazar Americano, 9(28). Recuperado de http://www.bazaramericano. com/columnas. php?cod=19\&pdf=si

Dalmaroni, M. (2016). La resistencia de lo imposible (una introducción). Estudios curatoriales, 3(4). Recuperado de http://untref.edu.ar/rec/num4_dossier_1.php

Didi-Huberman, G. (2009). La imagen superviviente. Historia del arte y tiempo de los fantasmas según Aby Warburg. Madrid: Abada Editores.

Didi-Huberman, G. (2011). Ante el tiempo. Historia del arte y anacronismo de las imágenes. Trad. Oscar Oviedo. Buenos Aires: Adriana Hidalgo Editora.

Didi-Huberman, G. (2012). Supervivencia de las luciérnagas. Madrid: Abada Editores.

Didi-Huberman, G. (2015). "Salir de plan(o)" en Hacer. Ensayos sobre el recomenzar. Maccioni, F. y Martínez Ramacciotti, J. (comp.). Buenos Aires: Teseo.

Foster, H. (2001). El retorno de lo real. La vanguardia a finales de siglo. Trad. Alfredo Brotons. Madrid: Akal Ediciones.

Garramuño, F. (2015) Mundos en común. Ensayos sobre la inespecificidad en el arte. Buenos Aires: Fondo de Cultura Económica.

García, L. (s.f.). La "actualidad” de Walter Benjamin. Giorgio Agamben, George Didi-Huberman y el problema de la temporalidad. Herramienta. Revista de debate y critica marxista. Recuperado de https://herramienta.com.ar/articulo.php?id=2131

Horne, L. (2011). Literaturas reales. Transformaciones del realismo en la narrativa latinoamericana contemporánea. Rosario, Argentina: Beatriz Viterbo Editora. 
Laddaga, R. (2007) Espectáculos de realidad. Ensayo sobre la narrativa latinoamericana de las últimas dos décadas. Rosario, Argentina: Beatriz Viterbo Editora.

Ludmer, J. (2007). Literaturas postautónomas. Ciberletras. Revista de crítica literaria y de cultura, (17). Recuperado de http://www.lehman.edu/faculty/guinazu/ciberletras/v17/ludmer.htm

Ludmer, J. (2010). Aquí América Latina. Una especulación. Buenos Aires: Eterna Cadencia Editora.

Maccioni, F. (2017). Contemporáneos del mundo: políticas de la imagen y del recomenzar en la obra de Joaquín O. Giannuzzi (1924 - 2004) y en otros poetas argentinos. Tesis doctoral, Universidad Nacional de Córdoba, Argentina. Recuperado el 24 de febrero de 2020 de https://ffyh.unc.edu. ar/secyt/wp-content/uploads/sites/22/2019/05/EBOOK_MACCIONI.pdf

Maccioni, F. y Martínez Ramacciotti, J. (comp.). (2015). Hacer. Ensayos sobre el recomenzar. Buenos Aires: Editorial Teseo.

Neuburger, A (2015) La historia en imágenes. Walter Benjamin y el concepto de actualidad. Constelaciones. Revista de Teoría Crítica, 7(7), 186-201. Recuperado de http://constelaciones-rtc.net/ article/view/1118

Oyarzún, P. (2015). Arte, visualidad e historia. Santiago de Chile: Universidad Diego Portales.

Rancière, J. (2009). El reparto de lo sensible. Estética y politica. Santiago de Chile: LOM Ediciones.

Rancière, J. (2011). El destino de las imágenes. Trad. Matthew Gajdowski. Buenos Aires: Prometeo Libros.

Richard, N. (2014). Diálogos latinoamericanos en las fronteras del arte: Leonor Arfuch, Ticio Escobar, Néstor García Canclini, Andrea Giunta. Santiago de Chile: Universidad Diego Portales.

Topuzian, M. (2013). El fin de la literatura. Un ejercicio de teoría literaria comparada. Castilla. Estudios de Literatura, (4), 298-349. Recuperado de https://revistas.uva.es/index.php/castilla/ article/view/174

Weigel, S. (1999). Cuerpo, imagen y espacio en Walter Benjamin. Una relectura. Buenos Aires: Paidós.

\section{ARTÍCULOS RECOMENDADOS}

Bejarano, A. (julio-diciembre de 2016). Poéticas del intruso. JacquesRancière, lector de Mallarmé. La Palabra, (29), 129-137.

Burgos López, C.R. (julio-diciembre de 2017). Melodramas con brujas, vampiros u hombres lobos: El caso Pie de Bruja de Carolina Andújar. La Palabra, (31), 211-225.

Diaconu, D. (enero-junio de 2017). La autoficción: simulacro de teoría o desfiguraciones de un género. La Palabra, (30), 35-52.

Maglia, G. (julio-diciembre de 2017). Paisaje, identidad y nación en el Caribe poscolonial: Edouard Glissant y Derek Walcott. La Palabra, (31), 89-99. 